\title{
Effectiveness of Ginger Water with Honey on Weight Loss among Obese Women
}

\author{
Reshmi $\mathrm{V}^{1 *}$, Priyanka $\mathrm{G}^{2}$ \\ ${ }^{1}$ Department of Obstetrics \& Gynecological Nursing, Saveetha College of Nursing, SIMATS, Thandalam, Chennai, Tamil Nadu, India \\ ${ }^{2}$ B.Sc (N) IV Year, Saveetha College of Nursing, SIMATS, Chennai, India
}

\begin{abstract}
DOI: $10.36348 /$ sijtcm.2020.v03i10.002 $\quad$ | Received: 03.11.2020 | Accepted: 14.11 .2020 | Published: 19.11 .2020
*Corresponding author: Reshmi V
\end{abstract}

\section{Abstract}

Obesity is a global epidemic .it has been linked to many chronic disease such as cancer, hypertension, diabetes, coronary heart disease, myocardial infarction. A body mass index (BMI) is calculated using the person's weight in pounds and height in inches using the BMI formula. Classification for overweight is a BMI range from 25-29.9 and greater 30 is considered obese. According to the BMI system, currently a worldwide estimation of 937 millions overweight adults and 396 million obese adults. Aims: The present study aim to reduce the weight used in ginger water with honey. The research design for study as the quasi experimental which is used to a study to assess the effectiveness of ginger water with honey on weight loss among obese women at community area (mappedu village). Result and discussion: The study shows that weight loss as shows statistically non significant at demographic variables and shows that age ,types of family, education socioeconomic status, religion, occupation the pretest mean score of weight loss score was 75.71 with standard deviation 2.06 and the post test means score of weight loss was 70.03 with standard deviation 2.32 . This clearly infers that ginger water with honey administered to obese women resulted in a significant reduction in the level of weight loss among obese women.

Keywords: Ginger Water with Honey, Obese Women, Weight Loss.

Copyright () 2020 The Author(s): This is an open-access article distributed under the terms of the Creative Commons Attribution 4.0 International License (CC BY-NC 4.0) which permits unrestricted use, distribution, and reproduction in any medium for non-commercial use provided the original author and source are credited.

\section{INTRODUCTION}

Obesity is the global epidemic. It has been linked to many chronic diseases such as cancer, hypertension, myocardial infarction, diabetes, coronary heart disease. A body mass index (BMI) is calculated using the person's weight in pounds and height in inches using the BMI formula. Classification for overweight is a BMI range from 25-29.9 and greater 30 is considered obese. According to the BMI system, currently a worldwide estimation of 937 million overweight adults. This creating a growing health care concerns in the United States for children adults. Younger generations are seeking health care due to chronic illness such as hypertension and diabetes as a result of obesity. Obesity also increases the mortality and morbidity in preexisting medical condition. This is one of the most common disorders and a very difficult one to treat or manage .According to FInkelstein and his colleagues, obese patients spent approximately 42 percent more in medical expenses compared to normal weight patient it is estimated that Americans spent more than $\$$ billions dollars on weight loss supplement.
Obese is due to many factors such as sedentary lifestyle, increase caloric intake, genetic predisposition, and other physiologic factors. The readily availability of fatty foods, surgery drinks and snacks contributed greatly to obesity. Sedentary lifestyle with little or no physical activities also worsen the condition genetic played an important role in obesity; children with obese parents are more likely to become obese themselves, Genetic influential has been estimated as high as 40$70 \%$ in developing obesity. Women are more likely to be obese that men. Ethnicity such as Africans, American and Mexican-Americans are more likely to be obese than other racial ethnic groups. People of lower socioeconomic status are also at risk of developing obesity regardless of their race.

Ginger is well known spice and flavoring material that has also been used in traditionally medicine in many areas. Ethanolic extract of ginger had a reducing impact level of blood glucose and reduce in high fat diet. Honey can be consumed fresh or stored by canning or bottling. Natural honey is available in all over the country and marketing not crude honey 
problems due to its unattractive appearance. ginger water with honey administered to obese patient in reduction in the level of weight.

\section{METHOD AND MATERIALS}

A Quasi experimental research design was used to conduct the study in community area (mappedu village) 60 samples were selected from community area by using a purposive sampling technique. The criteria for sample selection are those who are understand the Tamil and English. Women available at the time of data collection. Those who have unconsented to participate in the study. Exclusion criteria are those who arenot understand the Tamil and English.not available at the time of data collection. Those who were not consented to participated in the study. Before commencing the data collection, authorized setting permission was obtained from the institution ethical committee of Saveetha institute of medical and technical sciences, followed by getting formal permission from the medical officer of community (mappedu village). The study was collected in Mappedu village from (15/03/2020) the data were collected for Four week. The investigator introduced and explained the purpose of of the study to sample and obtains the written consent. The demographic data were collected using effectiveness of ginger water with honey on weight loss in obese women was assessed. The BMI level checked before giving ginger water with honey among obese women. Then the ginger water with honey given and after the level of BMI rechecked among obese women. The were analyzed using descriptive method the sample characteristics were described using frequency and percentage co effectiveness was used. To assess the effectiveness of ginger water with honey among obese women. The associate the posttest level of weight loss with giving ginger water with honey and selected demographic variables of community area (mappedu village).

\section{RESULT AND DISCUSSION}

A total study of 60 individual participants in the study from the community area (mappedu village)

\section{Section a: description of the demographic variable of the women}

TABLE 1: Shows that most of the obese women $3(55 \%)$ were in the age group of 25 to 30 , $41(68.4 \%)$ were Hindu, 31(51.7\%) belongs to joint family, $36(60 \%)$ were graduates, $30(50 \%)$ belonged to middle class, $31(51.7 \%)$ were unmarried and $30(50 \%)$ were unemployed.

\section{Section b: assessment of level of weight loss among obese women.}

Table-1

\begin{tabular}{|l|c|c|c|c|c|c|c|c|}
\hline \multirow{2}{*}{$\begin{array}{c}\text { Menstrual } \\
\text { Distress }\end{array}$} & $\begin{array}{c}\text { Under } \\
\text { Weight }\end{array}$ & \multicolumn{2}{c|}{$\begin{array}{c}\text { Normal or Healthy } \\
\text { Weight }\end{array}$} & \multicolumn{2}{c|}{ Overweight } & \multicolumn{2}{c|}{ Obese } \\
\cline { 2 - 10 } & No. & $\%$ & No. & $\%$ & No. & $\%$ & No. & $\%$ \\
\hline Pretest & 0 & 0 & 0 & 0 & 0 & 0 & 60 & 100.0 \\
\hline Post Test & 0 & 0 & 0 & 0 & 0 & 0 & 60 & 100.0 \\
\hline
\end{tabular}

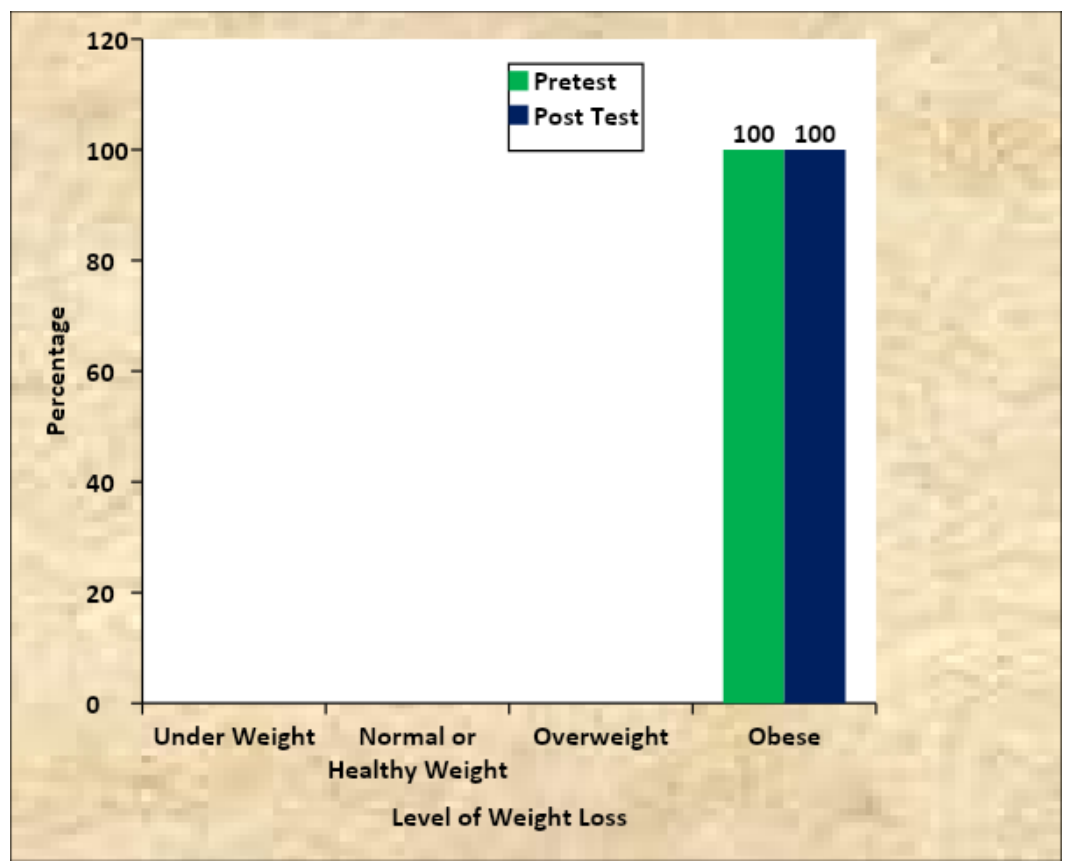


TABLE 2: The above table 2 shows that in the pre test, all 60(100\%) were obese whereas in almost all $60(100 \%)$ were obese.

Section C: effectiveness of ginger water with honey on weight loss among obese women

Table-2

\begin{tabular}{|l|l|c|c|}
\hline WEIGHT LOSS & MEAN & S.D & Paired "t" test value \\
\cline { 1 - 3 } Pretest & 75.71 & 2.06 & $\mathrm{~T}=40.398$ \\
\cline { 1 - 2 } Post test & 70.03 & 2.32 & $\begin{array}{l}\mathrm{P}=0.0001 \\
\mathrm{~S} * * *\end{array}$ \\
\hline
\end{tabular}

TABLE 3: The table 3 depicts that the pre test mean score of weight loss score was 75.71 with standard deviation 2.06 and the post test mean score of weight was 70.03 with standard deviation 2.32 . The calculation paired " $t$ " test value of $t=40398$ was found to be statistically highly significant at $<0.001$ level. This clearly infers that ginger water with honey administered to obese women resulted in a significant reduction in the level of weight among obese women.

\section{Section d: association of level of weight loss with selected demographic variables}

TABLE 4:The table shows that the demographic variables age had shown statistically significant association with post test mean score of weight loss among obese women at $p<0.05$ level and the other demographic variables had not shown statistically women.

\section{CONCLUSION}

This chapter as deals with analysis and interpretation of the data collected from 60 obese women in community area (Mappedu village). this chapter clearly brings out of the findings of the study the data was analysed based on the objectives of the study and were presented in the tables and figure.The findings shows that post test mean score of weight 70.03 with standard deviation 2.32.the women had no significant association was found age, types of family ,education, occupation, religion, socio economic status.this system of practice followed as not statistically and almost the same type of problems was faced by the womens in different community.

\section{ACKNOWLEDGEMENT}

We would like to extend our gratitude to the authorities of Saveetha College of nursing

\section{Author's contribution}

All the authors actively participated in the work of the study. All the authors read and approved the final manuscript.

\section{Conflicts of interests}

The authors declare no conflicts of interest

\section{REFFERENCE}

1. Shao, Q., \& Chin, K. V. (2011). Survey of American food trends and the growing obesity epidemic. Nutrition research and practice, 5(3), 253-259.

2. SJ, T. L. (2000). Papadakis MA (eds) Current medical diagnosis and treatment.

3. Finkelstein, E. A., Trogdon, J. G., Cohen, J. W., \& Dietz, W. (2009). Annual Medical Spending Attributable To Obesity: Payer-And ServiceSpecific Estimates: Amid calls for health reform, real cost savings are more likely to be achieved through reducing obesity and related risk factors. Health affairs, 28(Suppl1), w822-w831.

4. Roberts, A. T., Martin, C. K., Liu, Z., Amen, R. J., Woltering, E. A., Rood, J. C., ... \& Greenway, F. L. (2007). The safety and efficacy of a dietary herbal supplement and gallic acid for weight loss. Journal of medicinal food, 10(1), 184-188.

5. Greenway, F. L., Liu, Z., Martin, C. K., Kai-Yuan, W., Nofziger, J., Rood, J. C., ... \& Amen, R. J. (2006). Safety and efficacy of NT, an herbal supplement, in treating human obesity. International journal of obesity, 30(12), 1737-1741.

6. Sharpe, P. A., Granner, M. L., Conway, J. M., Ainsworth, B. E., \& Dobre, M. (2006). Availability of weight-loss supplements: Results of an audit of retail outlets in a southeastern city. Journal of the American Dietetic Association, 106(12), 2045 2051.

7. Afzalpour, M. E., Khiyabani, S., Abtahi Eivari, S. H., \& Nayebifar, S. (2017). Effects of high intensity interval training and ginger supplement on some antioxidant markers, cardio-respiratory fitness and body mass index in overweight women. Koomesh, 19(3), 703-711.

8. Afzalpour, M. E., Nayebifar, S., Kazemi, T., Abtahi-Eivary, S. H., \& Mogharnasi, M. (2016). Determination of atherosclerosis markers changes after hiit and ginger consumption in response to acute exercise in overweight women. J. App. Pharm. Sci, 6, 78-84.

9. Al-Amin, Z. M., Thomson, M., Al-Qattan, K. K., Peltonen-Shalaby, R., \& Ali, M. (2006). Antidiabetic and hypolipidaemic properties of ginger (Zingiber officinale) in streptozotocin-induced 
diabetic rats. British journal of nutrition, 96(4), 660-666.

10. ALIZADEH, J., SHIRZADI, A., SOHRABI, A., \& DABIDI, R. V. (2015). Effect of the exercise in water and ginger supplementation on cardio metabolic risk factors in obese women with breast cancer.

11. Al-Noory, A. S., Amreen, A. N., \& Hymoor, S. (2013). Antihyperlipidemic effects of ginger extracts in alloxan-induced diabetes and propylthiouracil-induced hypothyroidism in (rats). Pharmacognosy research, 5(3), 157.

12. Amato, M. C., Guarnotta, V., \& Giordano, C. (2013). Body composition assessment for the definition of cardiometabolic risk. Journal of endocrinological investigation, 36(7), 537-543.
13. Atashak, S., Azarbayjani, M. A., Piri, M., \& Jafari, A. (2012). Effects of combination of long-term ginger consumption and resistance training on lipid peroxidation and insulin resistance in obese men. Journal of Medicinal Plants, 2(42), 179-188.

14. Atashak, S., Peeri, M., Azarbayjani, M. A., \& Stannard, S. R. (2014). Effects of ginger (Zingiber officinale Roscoe) supplementation and resistance training on some blood oxidative stress markers in obese men. Journal of Exercise Science \& Fitness, 12(1), 26-30.

15. Atashak, S., Peeri, M., Azarbayjani, M. A., Stannard, S. R., \& Haghighi, M. M. (2011). Obesity-related cardiovascular risk factors after long-term resistance training and ginger supplementation. Journal of sports science \& medicine, 10(4), 685. 